\title{
Pulso entre poderes en el Nuevo Reino de León, 1723-1731: el gobernador Arriaga y el regidor García de Pruneda
}

\author{
Pulse between powers in the Nuevo Reino de León, 1723-1731: \\ the governor Arriaga and the alderman García de Pruneda
}

\author{
Ascensión Baeza Martín*
}

RESUMEN

Centrado en la región fronteriza del Nuevo Reino de León en las primeras décadas del siglo XVIII en donde la convivencia entre colonos e indios seguía siendo como en otro tiempo conflictiva, este trabajo indaga las relaciones entre el poder provincial y el municipal, su estructura, vínculos y efectos. A través, principalmente, del análisis de procesos judiciales se reconstruye las motivaciones de sus enfrentamientos y se subraya la fuerza del poder local cuando a las ya tradicionales redes familiares y clientelares se sumaba la acumulación de cargos en un mismo individuo.

Palabras Claves: Nuevo Reino de León. Colonos. Indios. Siglo XVIII. Enfrentamientos. Gobernador. Regidor. Venta de oficios.

\begin{abstract}
Centered in the border region of the Nuevo Reino de León in the first decades of the 18th century where coexistence between settlers and Indians remained at another time conflict, this work explores the relationship between the provincial power and the city, its structure, links and effects. Through, mainly, the judicial process analysis reconstructs the motivations of their clashes and underlines the strength of local power when to the traditional familiary nets and clients added to the accumulation of charges in one individual.
\end{abstract}

KEYWORDS: Nuevo Reino de León. Settler. Indians. $18^{\text {th }}$ century. Confrontations. Governor. Alderman. Sale offices.

Es notorio que los enfrentamientos entre grupos de poder son y han sido frecuentes a lo largo de la Historia con independencia del ámbito geográfico, del momento y de los motivos. En muchos casos han provocado debates y pleitos más o menos dilatados en el tiempo y arduos o imposibles de resolver por su especial complejidad. A veces, han destapado alianzas y corrupciones que afectaban no sólo a los intereses profesionales y particulares de los litigantes, sus familias y asociados, sino a la institución por ellos representada. Inmersos en la América colonial en los decenios iniciales

\footnotetext{
* Doctora en Historia de América por la Universidad de Sevilla/España. Licenciada en Historia de América por la Universidad de Sevilla/ España. Maestra de Primera Eenseñanza por la Escuela Normal de Magisterio de Sevilla/ España. Ayudante Técnico.Sanitario- Diplomada Universitaria en Enfermería por la Escuela de Enfermería de la Facultad de Medicina de Sevilla/ España. Miembro hasta finales del 2009 del Grupo de Investigación "Tierra y Sociedad" dirigido por el Profesor Dr. D. Luis Navarro García del Departamento de Historia de América de la Facultad de Geografía e Historia de la Universidad de Sevilla/ España.
} 
del siglo Ilustrado, este trabajo se encuadra en el Nuevo Reino de León, territorio de la frontera nordeste del virreinato de Nueva España. Era una época de recrudecimiento de las hostilidades de los indios apóstatas y gentiles en esos confines, de casi permanente conflicto bélico con los colonos. ${ }^{2}$

Al igual que se había efectuado en otras ocasiones, también entre 1713-1714 se hicieron intensas denuncias al virrey novohispano y a la Corona por parte de autoridades civiles y eclesiásticas del Nuevo Reino de León y de México acerca de su ruinosa situación. El caos estaba propiciado, por un lado, por las agresiones de los indígenas a los vecinos y sus propiedades y, por el otro, por los estragos que estos últimos hacían a los indios sacándolos con violencia de sus reductos, vendiéndolos o teniéndolos esclavizados y a su servicio en las congregas. Esta insufrible y endémica realidad predispuso a que se enviara en diciembre de 1714, previa J unta de Guerra y Hacienda y decreto del virrey duque de Linares, al alcalde del Crimen de la Audiencia de México Francisco de Barbadillo Vitoria. Ni las instrucciones suministradas al comisionado a fin de regenerar el estado de esa provincia, ni las medidas que conforme a ellas aplicó para que se suprimieran las congregas y fundasen pueblos de indios o se formara una compañía volante, entre otras, perduró. Pronto se comprobaría que los efectos no eran los esperados. ${ }^{3}$

\section{Perfil de los Adversarios}

El gobernador, J uan J osé de Arriaga Brambila, era criollo. Había nacido en la capital mexicana y se le bautizó en la catedral el 23 de octubre de 1679. Hijo de Francisco de Arriaga Bocanegra y de su segunda esposa Ana de Esquivel Castañeda, de familias nobles de México y descendientes de conquistadores de Nueva España, estudió en el Colegio de San Pedro y San Pablo de la Compañía de J esús de esa capital y en la Universidad. En 1697, por petición de su padre que había ocupado diversas alcaldías mayores en ese virreinato y en 1683 fue alcalde ordinario del Ayuntamiento de México, se declaró en dicho cabildo que aquel era hijo legítimo suyo y digno de que el rey le honrara con cualquier cargo político o militar.

2 Las contiendas que se producían no eran guerras propiamente dichas sino episodios eventuales y parciales de luchas. (HOYO, 1972, v. 1, p. 317). Aportan información sobre los indígenas de esta zona, (VALDÉS, 1995; SHERIDAN PRIETO, 2002). Un enfoque global de esta región en (NAVARRO GARCÍA, 1964; GERHARD, 1996; J IMÉNEZ NÚÑEZ, 2006).

3 Datos de la labor de Barbadillo que muestran el estado de la cuestión en cuanto a las relaciones colonos-indios, características de las congregas y otras particularidades de esta región en (ZAVALA, 1992, p. 111-117; MONTEMAYOR HERNANDEZ, 1970, p. 564-575). 
El 23 de julio de 1713 se le concedió por cinco años la alcaldía mayor de Singulica y Tulanzingo (México) por la que pagó 1000 pesos. En el juicio de residencia que se le hizo al finalizar su labor, resultó exento de cargos, según figura en su relación de méritos. En 1721 fue elegido diputado de la Archicofradía de Caballeros de México.

Mediante las comisiones que entre 1721-1722 le confiaron por un lado la Sala del Crimen de la Audiencia de México en Tulanzingo y por otro el alcalde mayor de San J uan de Teotihuacán, apresó a algunos peligrosos delincuentes y salteadores de caminos. Impidió que se fabricaran aguardientes y mistelas con substancias consideradas nocivas, pese a que se le ofrecieron grandes sumas de pesos para que disimulara y permitiera su elaboración. Efectuó algunas mediciones de tierras, costeó de su caudal varias obras dirigidas a contener las inundaciones e hizo fabricar las casas reales de Acaxochitlán y que se reedificaran las de Atotonilco y Singuinulco. ${ }^{4}$

El 5 de mayo de 1723 tomó posesión del empleo de gobernador y capitán general del Nuevo Reino de León. Tenía 45 años y estaba casado con J osefa Martínez Borrego. Un puesto que, según parece, lo obtuvo mediante el abono de 16.000 pesos al marqués de Villapuente, hombre poderoso de México, que fue quien se lo revendió. ${ }^{5}$

El regidor perpetuo y alcalde provincial de la Santa Hermandad de Monterrey, Luís García de Pruneda, era peninsular. Había nacido en Santibáñez en el Valle de Carriedo en las montañas de Burgos y pasó a Indias hacia 1676 con su tío Domingo de Pruneda electo gobernador de Nuevo León. Como muchos de los emigrantes españoles que se marcharon a América, utilizaría una serie de estrategias que fueron encumbrándolo social, política y económicamente hasta formar parte de la élite de dicha región y ser uno de los vecinos más acaudalados. Se casó con J uana de León, hija de Agustina de Cantú y del general Alonso de León célebre por sus campañas para la pacificación del Nuevo Reino de León y por ser el primer descubridor y conquistador de la Bahía del

4 Partida de bautismo de Juan J ose de Arriaga y Declaración de los alcaldes ordinarios Agustín Urrutia de Vergara y Alfonso Flores de Valdés, México, 23 de octubre de 1679 y 15 de febrero de 1697, Archivo General de Indias (AGI), Audiencia de México, leg. 566. Real título a J uan J osé de Arriaga, Madrid, 26 de julio de 1713, ibid. Relación de los méritos y servicios del capitán D. Francisco de Arriaga Bocanegra Brambila, Madrid, 18 de diciembre de 1679, AGI, Indiferente General, 127, N.108. A veces, los apellidos aparecen en distinto orden. Árbol genealógico de J uan J osé de Arriaga Brambila, México, 19 de enero de 1728, AGI, Mapas y Planos-Escudos, 321.

5 Relación de los servicios de D. J osé de la Puente y Peña, Madrid, 4 de agosto de 1696 y 28 de abril de 1704, AGI, Indiferente General, 134, N.19 y 136, N. 158. Tras haber sido gentilhombre de Cámara del rey y regidor de la Villa de Madrid, comenzó su ascenso social en Nueva España al participar en la extinción del tumulto ocurrido en México el 7 de junio de 1692 por lo que se le nombró capitán de infantería de un tercio miliciano formado por comerciantes. Por otros servicios obtendría sucesivamente el grado de maestre de campo, un hábito de la Orden de Santiago y el título de marqués de Villapuente de la Peña. Era dueño de haciendas de ganados mayores y menores que iban a pastar al Nuevo Reino de León. 
Espíritu Santo y provincia de Texas y durante 17 años gobernador de Coahuila (CAVAZOS GARZA, 1986, p. 120-121; PEÑA GUAJ ARDO, 2005, p. 63).

Entre las actividades económicas desarrolladas por García de Pruneda estarían el comercio, la cría de ganado mayor, menor, caballar, mular y el préstamo y llegaría a poseer grandes extensiones de tierra al sur de esa región. Poco a poco se iría introduciendo en los círculos de poder político, ya mediante el beneficio de los empleos de regidor y alcalde de la Hermandad por los que desembolsó 450 pesos, ya en puestos militares o de gobierno, pues ejerció un año de teniente y capitán del presidio de San J uan de Cadereyta y fue gobernador del Nuevo Reino de León a partir de 1708 al fallecer su hermano Cipriano García de Pruneda —una de las grandes fortunas de la primera década del siglo XVIII de esa región- que era quien ocupaba el cargo desde 1707. (COVARRUBIAS, 1961, p. 15, 19-20; PEÑA GUAJARDO, 2005, p. 63-65. En 1710, el virrey Alburquerque le agradeció su eficaz intervención en la reducción y población de los indios gentiles de ese territorio y su aportación económica al pueblo de Nuestra Señora de Guadalupe. Cooperó con Francisco de Barbadillo Vitoria en la ya citada empresa encomendada por el virrey Linares en 1714; ayudó a la manutención de misioneros; sufragó ornamentos y donó imágenes de Cristo crucificado y J esús Nazareno.

En su etapa de juez de comisión de tierras midió las del pueblo de San Cristóbal de los Gualagüises. En su hoja de servicios consta que rechazó los 300 pesos y 400 carneros que le ofrecía el cabildo de la Villa de Linares para que suspendiese la medición y costeó de su peculio los 300 pesos asignados a sus colaboradores en esta tarea.

Se ocupó, parece que también a sus expensas, del abastecimiento de agua en la ciudad de Monterrey, del arreglo de sus calles y edificios y de la construcción de pósitos. Llegaría a ser asentista de la Real Fábrica de la pólvora y juez visitador de registros de hierros y señales de ganado. Decía haber defendido el derecho del Real Patronato en un asunto relacionado con el secuestro de misiones por el obispo de Guadalajara Diego Camacho y Ávila. Desempeñó el cargo de Mayordomo del Santísimo de la ciudad de Monterrey, pagó el aceite y la cera del que antes carecía, regaló ornamentos, blandones y un valioso palio. Con el tiempo, fundaría una capellanía por 6.000 pesos.

Desde 1719 fue teniente de Barbadillo, gobernador de esas tierras después de su comisión. A la marcha de éste en 1723, se hizo con el mando interinamente hasta la llegada del designado. García de Pruneda tenía creído que se quedaría como gobernador y así lo había difundido entre varios vecinos. Al conocer que iba Arriaga comentó que "era cosa indigna que un criollo fuese gobernador al Nuevo Reino de León". ${ }^{6}$

${ }^{6}$ Relación de los méritos de D. Luís García de Pruneda, Madrid, 15 de marzo de 1738, AGI, Indife- 


\section{Origen, Curso de la Pendencia y Órden de Hacer una Pesquisa7}

La porfía entre el que fuera gobernador de ese territorio y el regidor tuvo principio poco después de la llegada del primero a Monterrey en 1723. Al lance inicial se le fueron uniendo otras querellas que agrandaron y prolongaron el pleito. A este respecto, Arriaga manifestaría que a su adversario le sobraba "maña para haber enredado, confundido y abultado el proceso" y estaba muy interesado en ir consumiendo el tiempo para ver si así conseguía ganar un pleito que de otra manera no lograría. ${ }^{8}$

Previamente a su venida, Arriaga le había escrito a García de Pruneda anunciándole su nombramiento. A su llegada, el edil se lamentaría de que teniendo que hacerle entrega en su condición de teniente de gobernador del bastón de mando, no hubiera usado con su persona de la cortesía requerida en estos casos. Tampoco había tenido la deferencia de escribirle a su hijo, el capitán, regidor y alguacil mayor de Monterrey Juan García de Pruneda, a su arribo y, en cambio, sí lo efectuó con otros vecinos de inferior categoría. Expresaba que a pesar de estas desatenciones, él no escatimó gastos, incluso de su propio caudal, en obsequios y cumplidos no sólo en la recepción, sino que hizo escoltar más de 100 cargas de mercancías que traía el nuevo mandatario, amén de dejarle abastecida la despensa "de todo lo comestible que ofrece el país". 9

Sin desestimar estos roces iniciales, la rivalidad en firme entre ambas autoridades empezó con motivo de las elecciones a alcaldes ordinarios y procurador en enero de 1723, cuando todavía García de Pruneda era gobernador interino. No convenció el resultado de las mismas al alcalde ordinario de Monterrey Pedro de la Barreda y presentaría un escrito al nuevo dirigente pidiendo la anulación. Juzgaba que de los dos alcaldes electos, J oaquín de Escamilla y Francisco de la Garza, uno no había dado la residencia del ejercicio anterior y el otro era analfabeto. Por otra parte, el sufragio se había llevado a cabo con sólo el voto de J uan García de Pruneda a quien "Ilaman hombre inepto, simple y le faltaba la razón y la edad por ser menor de 25 años”. El regidor decano Luis García de Pruneda, calificó el escrito de infamatorio y pretendió que Arria-

rente General, 148, N. 23. Certificación de Juan Álvarez de la Plata, México, 26 de junio de 1725, AGI, Audiencia de Guadalajara, leg. 118.

7 Ofrecimos un avance sobre algunos aspectos de esta disputa en (BAEZA MARTÍN, 2009, p. 151165).

8 Certificación de Luis de Benavides, México, 10 de mayo de 1727, AGI, Audiencia de México, leg. 566.

9 Certificaciones de Juan Álvarez de la Plata, México, 29 de agosto de 1725 y 29 de octubre de 1729, AGI, Audiencia de Guadalajara, leg. 118. Con estos y otros testimonios hechos a petición de Luis García de Pruneda, este escribano da fe de una serie de documentos y papeles que le fue presentando para tal efecto, entre ellos la citada carta de Arriaga y diversos expedientes generados en el transcurso del pleito. 
ga se abstuviera del conocimiento de esta causa. Discurría que los reparos de Barreda no eran legítimos ni legales, amén de que ya había dado cuenta de los comicios al virrey y si quería reclamar algo, acudiera allí o pidiera lo que a su derecho conviniere.

En esta coyuntura, a Arriaga le llegaron rumores de que el decano y su "correveidile" J osé Manuel de Arredondo difundieron casa por casa que el escrito de Barreda era denigrante al haber llamado a los alcaldes elegidos indios, mulatos, simples e incapacitados. J uzgaba el gobernador que con ello movían los ánimos e inquietudes populares contra Barreda, ya que estaban todos muy emparentados. A esto se añadía que tanto dicho alcalde ordinario como el regidor tenían seguidores y podían recurrir a las armas y provocar una revuelta, como ya lo habían intentado en la misma jornada de las elecciones, incidente que se evitó fuera a más al no acudir el primero al cabildo y dejar que el segundo actuara a su libre albedrio.

Ante la dificultad de hacer constar a los vecinos que no era cierto lo propagado por García de Pruneda y Arredondo, ni de mostrarles el escrito de Barreda para su comprobación, Arriaga optó por decretar prisión para el segundo. Al primero se le debería de advertir que no alterase al vecindario, so pena de la vida y traidor al rey, convocándole a que acudiera a su morada a fin de comunicarle formalmente esta resolución.

El día 15 de junio de 1723, una vez en su presencia y actuando como asistentes el sargento Pedro de las Fuentes y el capitán J osé Félix de Almandos y siendo testigo Diego de Alemán, le fue leído el despacho por el capitán Roque Pérez de Salgo. Finalizada la lectura, García de Pruneda desafió a su superior con un fuerte golpe en la mesa exclamando encolerizado que a "hombres de su tamaño no se le notificaban tales autos". Arriaga le agarró de la corbata respondiéndole que era "un pícaro de pocas obligaciones y de ninguna honra" y le previno que se contuviera o lo mandaría ejecutar a usanza de guerra por inobediencia. La risotada del subordinado acompañada de gestos provocadores, incitó al gobernador a agredirle fisicamente y, más tarde, a realizar unas diligencias con la declaración de las personas presentes en el trance para dar cuenta al virrey.

Esta causa se unió a la que estaba siguiendo el propio Arriaga por una denuncia que el capitán Francisco Antonio Dávila había puesto anteriormente contra el regidor decano acerca del mal uso en el ejercicio de sus oficios; la falta de confirmación de los mismos; la colusión que hubo con el juez que lo residenció y de varios excesos más. ${ }^{10}$

10 Certificación de Luis de Benavides, México, 10 de mayo de 1727, AGI, Audiencia de México, 566. 
El encuentro entre Arriaga y García de Pruneda fue relatado con notables diferencias por uno y otro y sus respectivos bandos y dio origen a que el segundo no sólo presentara una querella por la agresión de su rival en el acto de la notificación sino que, como ya hemos referido, fue añadiendo algunas más. Entre ellas, una en la que lo acusaba de haber llevado mercancias a ese Reino y venderlas en su propia casa o la de haber propiciado matanzas de indios pacificados o su venta.

Así, pues, los puntos a tratar en el pleito eran varios. El fiscal de la Audiencia de México, Pedro Malo de Villavicencio, destacaba en su dictamen "el ardimiento" de Arriaga en el modo con que actuó contra su subalterno y su desatino al proceder a indagar por medio de testigos una causa que ya estaba pendiente en el superior gobierno de México. Tanto el fiscal como J osé Méndez, asesor del entonces virrey marqués de Casafuerte, estimaban que debía de hacerse una pesquisa. Méndez intuía que unas diligencias "de tan grave asunto y difícil práctica”, requerían en el encargado de realizarlas, "no sólo capacidad, sino autoridad y respeto correspondiente a lo remoto de aquel reino y poder de una y otra parcialidad [...]". Sugería que se facultara a un ministro togado y proponía que a efectos de la investigación el virrey debería mandar lo siguiente:

1) La reclusión de Luis García de Pruneda en las casas del cabildo de México a donde había acudido después de la disputa con Arriaga.

2) Que el pesquisidor indagase primero sobre la reyerta y se informara extrajudicialmente con toda reserva, acerca del trato y comercio que el regidor decano atribuía al gobernador. A la vista de los resultado podría el virrey tomar otras resoluciones.

3) Que dicho comisionado examinara el libro de cabildos y tomara declaración a los alcaldes. Si era cierto que la elecciones de 1723 se celebraron con sólo el voto de J uan García de Pruneda, las anularía y depositaría las varas en dos sujetos idóneos y de su satisfacción y los más independientes posibles de uno y otro bando. Aconsejaba Méndez un mayor número de capitulares en el cabildo de Monterrey con el fin de evitar que se repitieran estos percances.

4) Que a pesar de que nadie podía ser juzgado dos veces por la misma causa una vez prescrito el plazo señalado, era factible conforme a la Ley 41, título 4, libro 2 de la Recopilación de las Leyes de Indias, hacer nuevas pesquisas acerca de los excesos que se imputaban a Luis García de Pruneda en el ejercicio de los oficios y comisiones que tuvo, si constara que hubo omisión o conclusión culpable en el juez que le tomó la residencia y sentenció. En ese caso, Francisco Dávila que fue quien lo demandó ante

Certificaciones de J uan Álvarez de la Plata, México, 26 de junio y 29 de agosto de 1725, AGI, Au- 
Arriaga tendría que dar una fianza 10.000 pesos. ${ }^{11}$

Casafuerte hizo las siguientes modificaciones al dictamen del asesor: la pesquisa se realizaría en lo tocante al trato y contrato atribuido por García de Pruneda al gobernador, dando la fianza de calumnia. Aunque resultara ser cierto el contenido del escrito de Barreda, no se reformaría la posesión de las varas hasta que remitidos los autos al superior gobierno ordenara lo que se debía de ejecutar. En cuanto al punto cuarto, la averiguación se centraría sólo en lo referente a delitos cometidos por el regidor decano en el uso de sus oficios, pero no en afrentas de particulares sin dependencia del empleo, pues "los agraviados harán su diligencia si quisieren”.

El 9 de septiembre dio comisión el virrey para la pesquisa al abogado de la $\mathrm{Au}-$ diencia de México, Francisco Antonio de Bustamante quien la aceptaría once días más tarde y nombró receptor y alguacil mayor de las diligencias a practicar al escribano Sebastián González de Mendoza. Una de sus primeras medidas fue la de que Arriaga saliera $30 \mathrm{Km}$ fuera del entorno de Monterrey, algo que no satisfizo a su oponente por entender que estaba demasiado cerca y podía influir en los testigos y solicitaría que la distancia fuera mayor. Su petición se desestimó al igual que otras, es el caso de una de su esposa pidiendo se la llamase a declarar al haber sido ofendida en su honor por dicha autoridad. Tampoco se tuvieron en cuenta otras solicitudes de Arriaga, como la de que Francisco de la Canal, paisano, amigo íntimo y apoderado de su adversario, saliera de esa jurisdicción por suponer que estaba influido por éste y tenía muchos compadres. $^{12}$

\section{La versión de Partidarios y Detractores}

El enfoque de lo sucedido entre ambas autoridades aparece en los documentos con una manifiesta parcialidad, lo que conlleva, naturalmente, a valorar con la máxima cautela las declaraciones de unos y otros. Testimonios, por otro lado, marcados por la contradicción en donde la sombra de la calumnia, el soborno, las verdades a medias, los rumores y la venganza están presentes y fueron, a su vez, instrumentos utilizados por los litigantes para desacreditarse mutuamente.

diencia de Guadalajara, 118.

11 Informe de Pedro Malo de Villavicencio y de J osé Méndez al Virrey, México 9 y 29 de julio de 1723, AGI, Audiencia de Guadalajara, leg. 118. Certificaciones de Juan Álvarez de la Plata, México, 26 de junio y 29 de agosto de 1725, ibid. Dávila no pudo entregar la fianza que se le señaló por no disponer de tal cantidad.

12 Decreto de Casafuerte, México, 17 de agosto de 1723, AGI, Audiencia de Guadalajara, leg. 118. Certificaciones de Juan Álvarez de la Plata, México, 26 de junio y 29 de agosto de 1725, ibid. 
No es objetivo de este trabajo hacer un análisis exhaustivo ni pormenorizado de lo que declararon en esa época las personas o grupos implicados o relacionados con el caso que nos ocupa, ni de exponer al detalle el cruce de acusaciones entre los demandantes. Se trata de ofrecer sólo una muestra, con la que intentamos aproximarnos a lo que pudo haber ocurrido y las circunstancias que lo rodearon. A través de esta profusión de alegatos, las voces de los testigos nos llevan a identificar, al menos en parte, quién era cada uno de los contrincantes, su círculo y manejos. A conocer, también, aspectos sociales, económicos y políticos propios de una región fronteriza alejada de México y a la vez tan conectada con ella por su contribución, junto con otras regiones, al sistema económico novohispano. De igual forma, a reflexionar acerca de la actuación del gobierno virreinal en aquellos confines.

Para las informaciones sobre la reyerta y la supuesta actividad comercial de Arriaga —prohibida repetidamente a los gobernadores- así como de otras cuestiones que atañen a este caso, Bustamante convocó a 34 testigos, la mayoría de los cuales no presenció la agresión, sino que narraron lo que vieron a posteriori o lo que oyeron decir a terceros. A efectos de seguir la pista sobre qué mercancias pudo haber llevado a su arribo declararon en un principio los arrieros que fueron a por las cargas. J osé González, expuso que condujo unos 42 fardos y Manuel Nieto e Hipólito López admitieron haber transportado algunos desde México. Los tres desconocían con exactitud el contenido de los bultos, pero sabían que había jabón, menaje de casa, camas, escritorios, espuelas, frenos, clavazón y algunos azadones y coas y que no llevó géneros de Castilla, China o de la tierra. Las cargas se entregaron a Diego de Alemán, compadre del gobernador, quien pagó los fletes. No habían oido comentar que el acusado comerciase géneros.

Por el contrario, otros testigos expusieron que los fardos se llevaron primero al palacio donde residía el gobernador pero, que por estar en ruinas, éste se mudó a otra casa y fueron trasladados allí. En declaraciones posteriores se expresaría que en esa vivienda existía un negocio con caudal facilitado por el marqués de Villapuente y regentada por Alemán en la que se comerciaba con los vecinos y soldados. El acusado referiría que eso era inexacto ya que él sirvió únicamente de mediador por su amistad con ambos. Había gente que afirmaba que Roque Pérez de Salgo era cajero y administrador de una tienda que Arriaga tenía en Boca de Leones.

El pesquisidor verificó que las elecciones de 1723 se celebraron con sólo los García de Pruneda, siendo el padre el presidente de las mismas. Los demás no acudieron por decir que estaban enfermos. Para inquirir la aptitud de los electos alcaldes ordinarios Francisco de Escamilla y Francisco de la Garza y el procurador Nicolás Lo- 
zano, se examinaron doce personas, aunque los interesados ya habían hecho saber por escrito la falsedad de lo manifestado por Barreda. La mayoría de los declarantes comunicaron que dichos funcionarios sabían leer y escribir, aunque también habían oido referir a algunos lo contrario. Unos cuantos afirmaban que el hecho de que J oaquín de Escamilla hubiera ejercido ese puesto en varias ocasiones no se debía a su amistad con el regidor decano, sino a que contaba con caudal para afrontar los gastos que traía consigo el empleo y comentaban que nunca hizo extorsiones. Casi todos ignoraban si este alcalde se había sometido al juicio de residencia. También quedó patente que los García de Pruneda no habían pedido la confirmación de sus oficios.

Bustamante, -que no se libraría de críticas por parte de ambos litigantes acerca de su supuesto favoritismo por el contrario-, dió por concluidas las diligencias el 2 de diciembre de 1723. Después de esta gestión, las pesquisas se ampliarían con distintos comisionados en esa provincia y en México. No faltarían los reproches o las recusaciones de los contendientes contra algunos de los ministros que llevaron esta causa. Es el caso de J uan de Oliván Rebolledo recusado por García de Pruneda y de J osé Gutiérrez de la Peña por Arriaga. ${ }^{13}$

En general, por la pesquisa y demás interrogatorios ulteriores sabemos que en relación con la reyerta, García de Pruneda -y luego algunos de los declarantes- expresaría que se había querellado contra el gobernador porque con patente escándalo y en gravísimo perjuicio del crédito de su persona y estado matrimonial, le injurió públicamente no sólo con palabras en extremo afrentosas sino de obra, para lo cual tenía preparadas en la mesa dos pistolas y un cuchillo. Le despojó de sus insignias, le ensangrentó la cara y mandó llamar a un sacerdote para que lo confesara y soldados que lo ejecutasen. Esta intentona no se consumó porque hubo personas que intervinieron para apaciguar el lance, pero le amenazó con acabar con él y su familia si lo demandaba. ${ }^{14}$

Sobre este percance, el alcalde ordinario del Ayuntamiento de Monterrey, el capitán Francisco J avier de Escamilla certificaba que el regidor decano había prorrumpido contra su superior con gran violencia "provocándole, riéndose y amenazándole". Estimando aquel que el ultraje que se le estaba haciendo como gobernador y capitán general se lo hacían también a la Corona, determinó que se le aplicara la sentencia ordinaria de muerte a usanza de guerra, medida que no se llevó a cabo.

13 Certificaciones de Juan Álvarez de la Plata, México, 26 de junio y 29 de agosto de 1725, AGI, Audiencia de Guadalajara, leg. 118. Petición de J osé de Liticia en nombre de Luis García de Pruneda al Rey, (s/f), ibid. Carta de García de Pruneda al Virrey, México, 4 de mayo de 1728, AGI, Escribanía de Cámara, leg. 204A.

14 Petición de J osé de Liticia en nombre de Luis García de Pruneda al Rey, (s/f), AGI, Audiencia de Guadalajara, leg. 118. 
Escamilla describe cómo por dichas mofas y amenazas le dio Arriaga tres puñetes en el rostro sin usar para ello ningún arma como había alegado aquel. El incidente se complicó al presentarse J uan García de Pruneda en defensa de su padre empuñando la espada con ademán de desenvainarla. Por este desacato lo mando detener, resolviendo que ambos quedaran presos en su domicilio. Al lesionado hubo que transportarlo entre cuatro hombres hasta su vivienda, allí guardó cama y se confesó, circunstancias que causarían irrisión entre los vecinos por conocer sus fingimientos. Su superior mandó que no saliese y le puso cuatro soldados costeados de su bolsillo para vigilarlo. Al sexto día se fugó saltando los corrales de su casa para ir, según él, a presentarse ante el virrey.

Parece que no era la primera vez que el aludido utilizaba estas artimañas. Como indicativo está el de una pelea que mantuvo con el alcalde ordinario Alonso Rodríguez de Carvajal, tras la cual simuló encontrarse en estado agónico y pidió que se le administraran los santos óleos "para pasar de injuriante a injuriado". Esta astucia, junto con otras que le salieron bien, le habían "prestado avilantez para mayores desórdenes".

Arriaga sostendría a lo largo de este litigio que la pasión de García de Pruneda hacia su persona era anterior a que se conocieran, por su condición de criollo. En referencia al altercado con el mismo, declararía que la "sonrisa, cabeceo y ademán de amenaza" de éste eran una provocación. Reconoció que por eso le había golpeado y le dijo "algunas palabras que entonces dictó la ira y después se borraron de la memoria". En su ánimo no estaba aplicarle la máxima pena, sino sólo "sosegar su soberbia y el dominio absoluto que en aquel reino tenía, donde ha sido el tirano de honras y haciendas". Explicaba que no le quitó personalmente el espadín ni el bastón de mando y no recordaba si dio órden para ello, pero que en caso de haberlo hecho, se trataba de un reo y como tal debía de ser despojado de sus armas e insignias. Se lamentaba de que habiendo tenido aquel sonadas reyertas con otros, no se le había dado la importancia que a ésta.

Realmente, algunos testigos desvelaron que el agredido tuvo pendencias con varios gobernadores y con muchos vecinos, quienes temerosos de los testimonios que levantaba a las personas con quienes litigaba, le habían tolerado muchos daños personales y económicos causados. Se jactaba, además, de que con su dinero se salía con todo lo que quería y "de que tenía en México parientes, amigos, agentes y empeños y que lo eran los señores oidores y fiscal y los secretarios de los virreyes".

Seguían narrando los informantes que aunque cuando fue Francisco Capelón a tomarle la residencia de gobernador se pensó que serían castigadas sus maldades, estas 
expectativas se frustraron. Su apoderado, Pedro Guajardo, ya difunto, "hombre poderoso y que tenía todas las aceptaciones en este reino", cogió con tanto empeño su defensa que hizo que mucha de la gente que iba a demandarle se retirara. Y si algunos lo hacían, los echaba o les exigía que dieran fianzas, con lo cual sus delitos quedaron impunes. Otros testigos ratificaban que García de Pruneda sobornó a Capelón prometiéndole un dinero que, una vez finalizada la residencia, no le dio. ${ }^{15}$

Los declarantes estaban convencidos de que estos abusos cometidos durante 20 años, se debían al poder que había ido logrando con el acopio de cargos. Y es que, García de Pruneda, además de haber ejercido de gobernador y teniente de gobernador y de ser regidor perpetuo y alcalde provincial de la Hermandad, desempeñaba, los dos de su hijo --regidor y alguacil mayor-- pese a que éste, por su minoría de edad, tenía asignado un teniente, J uan Muñoz de Herrera, cajero de su padre y luego su yerno. Este acaparamiento de cargos hacía que pusiera en el cabildo a los alcaldes que le parecía, los cuales "ya por hechura suya, por agradecidos o por temor de sus violencias y cavilosidades" obedecían ciegamente sus mandatos. Dichos empleos que debían de servir para administrar justicia, los había convertido "en cañas de pescar los bienes ajenos". ${ }^{16}$

Realmente, el regidor decano estaba muy interesado en adquirir cargos sin importarle el coste. Había otorgado poder a J uan Francisco de las Navedas, vecino de México, para que solicitara cualquier oficio que el rey confiriese para las provincias de Nueva España al precio que fuera. También suministró dinero a Francisco de Mier Noriega, vecino de Monterrey, para que pujara por la plaza de escribano público de Nuevo León, con la cláusula de que una vez obtenido el empleo, le entregara la mitad de lo que cobrase por los derechos más un 7\% y de que en caso de que éste falleciera, pudiese él nombrar y renunciar el oficio en quien le pareciese. ${ }^{17}$ Con esta atadura conseguiría que este escribano le facilitara varios testimonios engañosos, entre ellos, uno de méritos servicios que no efectuó. Aparte de estos oficios y entre cargo y cargo, este

15 Certificación del capitán Francisco J avier de Escamilla, Ntra. Sra. de Monterrey, 20 de agosto de 1723, AGI, Audiencia de México, leg. 566. Certificación de Juan Álvarez de la Plata, México, 26 de junio de 1725, AGI, Audiencia de Guadalajara, leg. 118. Certificación de Juan de Guzmán (s/f), AGI, Escribanía de Cámara, leg. 204A. Este escribano da testimonio del alegato de Arriaga a las acusaciones de su adversario. (CAVAZOS GARZA, 1973, p. 129). Expone otro de los excesos de García de Pruneda.

16 Certificación del capitán Francisco Javier de Escamilla, Nuestra Señora de Monterrey, 20 de agosto de 1723, AGI, Audiencia de México, leg. 566. Certificación de Juan Álvarez de la Plata, México, 29 de agosto de 1725, AGI, Audiencia de Guadalajara, leg. 118. Certificación de Juan de Guzmán,(s/f), AGI, Escribanía de Cámara, leg. 204 A.

17 La renuncia que hizo Mier y Noriega de dicho oficio quedaría anulada y, a su muerte, se subastó y adjudicó a un postor por 700 pesos. Real título de escribano público a J osé Fernández Fajardo, San Lorenzo, 23 de octubre de 1738, AGI, Audiencia de Guadalajara, leg. 80. 
hombre, que siempre había "procurado tener algún mando", consiguió varias comisiones.

En cambio, otros de los testigos de este pleito estaban en contra de Arriaga y de sus operaciones. Así por ejemplo, Juan de Arellano, comisario del Santo Oficio y cura de Monterrey, manifestó que desde que llegó a esa región empezó a tratar a los vecinos de forma tan denigrante que "inconsolablemente se tragan los suspiros sin atreverse a prorrumpir sus justas quejas y aún los que se habían arriesgado a hacerlo quedaron públicamente difamados y deshonrados". Refería haber escrito al virrey avisándole de que no era idóneo para el cargo. Claro que, este sacerdote junto con su primo hermano Ignacio Martínez, también cura y apoderado de García de Pruneda, lo que pretendían con estas acusaciones, según testimonio de fray Francisco Llaveros, comisario visitador de los conventos y misiones del Nuevo Reino de León y experto conocedor de esa tierra, era que echaran a Arriaga y ocupase la plaza su adversario. ${ }^{18}$

El escribano J uan Álvarez de la Plata certificó que conocía al gobernador desde hacía más de 25 años y que por su "intrépito natural” se le apodaba “J uanico de Arriaga”. Lo acusaba de violento y de que por haber intentado quemar la picota de la plaza mayor de México y cometido otros desmanes lo desterraron a Filipinas. Una vez que regresó se dedicó sólo al juego y con ello a crear disputas y pleitos, llegando a matar a un sujeto llamado Pedro Benítez y, aunque se le impuso una pena de dos años de destierro, no los cumplió. Atestiguaba el escribano que cuando fue alcalde mayor de Tulanzingo cometió numerosas tropelías con los vecinos, muchos de los cuales fueron a México a quejarse, pero que por respeto y miedo de un hermano cura que tenía en esa jurisdicción, Francisco de Arriaga, no prosiguieron.

En este cruce de denuncias, García de Pruneda y sus parciales imputarían del mismo modo a su oponente de que en sus visitas a la tierra forzaba a jugar a los naipes a soldados y vecinos y hasta que no perdían no los dejaba marcharse o les obligaba a pagar la deuda con servicios personales. Esto, según el alcalde mayor y capitán de la Villa de Cadereyta, Miguel Leal, seguidor de Arriaga, era incierto. Aclaraba, que se tenía por costumbre desde tiempos remotos en Nuevo León, que los gobernadores en la visita general jugaran a las cartas para poder costearla con sus ganancias. Señalaba como caso singular el de dicho gobernador, pues habiéndolo acompañado él en todas sus visitas comprobó que las pocas veces que jugó fue sólo alguna "pachanga o renegado" con personas ricas de esa región.

18 Certificación de Juan de Arellano, Nuestra Señora de Monterrey, 27 de octubre de 1724, AGI, Audiencia de Guadalajara, leg. 118. Declaración de fray Francisco Llaveros, Cadereyta, 23 de octubre de 1724, AGI, Audiencia de Guadalajara, leg. 173. 
Arriaga se asombraba de que los mismos excesos que algunos declarantes le atribuían a su rival, se los achacara éste a su persona. Ciertamente, en lo relativo a los naipes hubo quien confirmó que cuando García de Pruneda fue teniente de gobernador, dio porciones de barajas de contrabando para que las vendieran en los juegos públicos a razón de 4 pesos cada una. Igualmente, lo hacía en su tienda a 12 reales o las remitía a distintas partes de esa región. En cuanto al comercio, también se supo que cuando fue gobernador despachaba por sí mismo en una tienda de su propiedad y al vecino que no le compraba o no sacara géneros fiado, lo alistaba para hacer campañas contra los indios - sin respetar las épocas de siembras o recolección- o lo deshonraba. En contraposición, favorecía a los clientes, a los cuales "desollaba la bolsa por los excesivos precios que les cargaba y les guardaba las vidas para que pudieran pagar". ${ }^{19}$

\section{El Capítulo de la Matanza de Indios}

[...] me parece duro caso hacer esclavos a los que Dios y naturaleza hizo libres.

Cervantes: El Quijote, I parte, cap. XXII

Otra de las graves acusaciones de García de Pruneda y sus seguidores contra Arriaga y que merece especial atención era la de que había consentido crueles matanzas de indios, incluso de los ya pacificados, por medio de guerras ofensivas o la venta de los que se capturaban en las campañas. ${ }^{20}$

Lo cierto es que unos meses después de su presencia en ese territorio, en cartas de 10 de agosto y 12 de septiembre de 1723 había dado cuenta Arriaga al virrey Casafuerte del lamentable estado en que lo había encontrado por los insultos, muertes y

19 Certificación de Juan Álvarez de la Plata, México, 26 de junio y 11 de diciembre de 1725, AGI, Audiencia de Guadalajara, leg. 118. Certificación de Juan de Guzman (s/f), AGI, Escribanía de Cámara, leg. 204A.

20 Certificación de Juan Álvarez de la Plata, México, 11 de diciembre de 1725, AGI, Audiencia de Guadalajara, legajo 118. Aseguraba que se vendían las mujeres e hijos de los indios. Certificación de Manuel Reyes Vivanco, Monterrey, 28 de abril de 1724, AGI, Audiencia de Guadalajara, 118. Este comisario general de la Santa Hermandad afirmaba que le habían avisado de que en el Real y Minas de Boca de Leones un sujeto había ahorcado a un indio cristiano y que sus huesos andaban rodando por el campo y lo mismo había ocurrido en varias partes de ese territorio. Para la averiguación de lo referido examinó a varias personas, todos vecinos de Monterrey, entre ellos el labrador J uan de la Mota. Éste refirió que era Arriaga quien había dado las órdenes para las muertes y estragos que habían sucedido en los pueblos, rancherías, montes y despoblados y, aunque esto era público y notorio nadie se atrevería a manifestarlo porque el virrey estaba conforme con lo hecho por aquel. Ninguno de los interrogados quiso firmar estas declaraciones, por lo que Vivanco fué a México, por tener noticias de que había personas que podrían ser examinadas sin que lo estorbara dicho gobernador. 
robos ejecutados por los indios apóstatas y gentiles en el distrito de su jurisdicción y de las lamentaciones y ruegos de los vecinos para que pusiera remedio. Le comunicaría, asimismo, que había hecho varias campañas a su costa. Que primero se intentó atraerlos por medios suaves, pero no queriendo aceptar la paz y continuado con sus ataques, se hizo guerra defensiva, habiendo muerto en las refriegas 46 indios y apresado a 33 muchachos que se repartieron entre los soldados.

Casafuerte le agradeció por escrito el desvelo que demostraban sus operaciones "tan del real servicio y de la causa pública en que espero continuará con el mismo rigor" y le instaba a que le informara de con qué fin se asignaban los prisioneros a los soldados. Esta expresión de gratitud sería utilizada interesadamente por Arriaga para tratar de demostrar a los demás el respaldo a sus actos y, tergiversadamente, por García de Pruneda y sus parciales para propagar que el máximo gobernante estaba a favor de Arriaga al haber ordenado en su misiva que prosiguiera en el exterminio de los indios. ${ }^{21}$

Se aprecia por las expresiones de los testigos de este litigio el modo con que percibían, como habitantes de ese territorio, la adversa situación en que se encontraba al arribo de la citada autoridad, las medidas practicadas por éste para su restauración y las estrategias utilizadas por los indios. Tácticas de estos últimos dirigidas a la aniquilación de sus moradores o a forzarlos a que abandonaran esas tierras, como consecuencia de sus tentativas de destruir el comercio basado, especialmente, en la ganadería y en menor escala en la agricultura y minería, tan esencial para su subsistencia.

A este respecto y tras la referida acusación contra el gobernador, el cabildo de Monterrey, un grupo de ganaderos, criadores y dueños de ganados mayores y menores y de haciendas, agostaderos y dehesas en que pastaban y abrevaban en el Nuevo Reino de León, así como más de 30 testigos civiles y eclesiásticos, saldrían en su defensa. En esencia, todos coincidían en que cuando llegó Arriaga a Monterrey, los indios enemigos tenían rodeado el reino y amedrentada a la vecindad con sus matanzas y robos. Su osadía había llegado a tal extremo que se tenía información de que pretendían arrasar la capital, por lo que los pobladores vigilaban de noche en las azoteas de sus casas prevenidos con las pocas armas que tenían.

Habían tomado todas las entradas y salidas de Monterrey, entre ellas, la de Santa Rosa y El Pilón y el paso por donde accedía el ganado de distintas regiones de Nueva España a pastar, de tal forma que no se podía transitar sin arriesgar la vida. También habían sacrificado y robado mucho ganado, sobre todo, caballos y mulas, no sólo para alimentarse de su carne o montar en ellos y hacerse más fuertes en la guerra,

21 Carta de Casafuerte a Arriaga. México, 8 de octubre de 1723, AGI, Audiencia de Guadalajara, 173. 
sino para que no teniendo los habitantes en qué cabalgar, se les hiciera más fácil su derrota.

Corroboraban el interés del nuevo gobernador en esta materia y de las campañas que se habían hecho costeadas por él para mitigar esta situación, ya que los indios no habían querido admitir la paz que les ofreció en diversas ocasiones. Aseguraban que las órdenes que dio fueron las de que se les atrajera pacíficamente y que en caso de ofrecerse guerra, fuera sólo defensiva. A raiz de lo cual quedó esa región con más seguridad de la que estaba inicialmente.

Consideraban que los indígenas que cometían esas maldades no sólo eran los gentiles o apóstatas, sino los ya evangelizados y reducidos a pueblos que se unían a los otros y que su atrevimiento había aumentado en tiempos del anterior gobernador, Francisco de Barbadillo Vitoria, porque sabían que no los iba a castigar. Otros testificaban que cometieron atrocidades "a vista, ciencia y paciencia y tolerancia" de García de Pruneda cuando ejerció el cargo de teniente de gobernador. En vez de impedir y castigar estas acciones las disimulaba, con lo cual los indios se insolentaron aún más. Destacaban que sólo él estaba exento de tales agravios, pues se había dado el caso de que habiendo cometido aquellos algún robo de caballos, en reconociendo por el hierro que eran suyos, los soltaban, lo que demostraba su confabulación con los indios. ${ }^{22}$

Para fray Miguel Pacheco, residente en esa región desde hacía 26 años, jamás se había visto tanta tranquilidad en el territorio, pues anteriormente no se podía transitar por parte alguna sin escoltas y ahora no era preciso llevarlas. Lo atribuía al gran celo y vigilancia de Arriaga, al que algunos llegarían a denominar el nuevo conquistador y pacificador de Nuevo León. No obstante, este mismo fraile en una carta dirigida un año antes a su comisario fray Sebastián de Torres reconocía que "por acá hay mucha carnicería de indios e indias, que han ahorcado 63 personas y las más sin confesión.” Le participaba que el capitán J uan García de Quintanilla esperó a que él se fuera a decir misa "para ahorcarlos sin confesión y sin culpa". ${ }^{23}$

22 Certificación del Cabildo de Monterrey, Monterrey, 31 de octubre de 1724, y Certificación del capitán Pedro del Valle, Real de las Salinas, 7 de junio de 1724, AGI, Audiencia de México, leg. 566. El primer documento fue firmado unánimemente por Andrés Guerra, Alonso García Cuello, Francisco Antonio Dávila, Pedro de Lizondo, Pedro de la Barreda Yebra, Francisco Báez Treviño y Nicolás de Ayala, siendo testigos J uan Francisco de Salinas y Diego de Alamán. Estas y otras declaraciones son el resultado de un informe mandado hacer por Arriaga referente a cómo estaba ese territorio a su llegada y de su actuación con los indios. Representación de los criadores de ganados del Nuevo Reino de León al Virrey, s/ f., AGI, Audiencia de Guadalajara, leg. 173. Firmaban esa representación en nombre de todos, J osé Cristóbal de Avendaño y Orduña, Gabriel Guerrero de Ardila, Alonso Ruiz de Medina, Luis de Monterde, el marqués de Villapuente, Isidro Rodríguez, J osé de Sorda, Juan de Baeza y Bueno, Francisco Valdivieso y Esteban de la Puente, gente influyente de México perteneciente al cabildo, Tribunal de Cuentas, comercio, etc.

${ }_{23}$ Certificación de fray Miguel Pacheco, Villa de San Gregorio de Cerralvo, 17 de octubre de 1724, 
El que había sido protector general de indios de esa región, Nicolás de Villalobos, denunció "las muertes, ventas y horrorosos estragos" de Arriaga y sus capitanes contra los indios y la esclavitud en que tenían algunos vecinos a los ya pacificados, con idea de que abandonaran los pueblos fundados por Barbadillo y quedarse ellos con las tierras. Esto lo achacaba a la falta de un protector que los amparase. Con ello parece que pretendía favorecer a los indios, pero también conseguir que se le restituyera el puesto del que había sido despojado. Un puesto que Arriaga no era partidario de que se restableciera y así se lo comunicaría al virrey, quien compartía esta idea por su inutilidad y coste.

Sin embargo, reconocía Villalobos, del mismo modo, que los indígenas eran muy vengativos. Manifestaba que en sus reuniones o juntas llamadas tlatoles, a los que acudían también mujeres, si una india anciana se ponía a llorar y decía que su llanto era por la muerte y ultraje que los españoles le habían hecho en determinado tiempo a su familia o nación y no había sido vengado, les incitaba a que lo hicieran, tachándolos de no tener honra si no consumaban el desquite. Esta instigación a la represalia tenía eco al día siguiente en que armados los indios y agrupados en escuadras, cuando menos lo esperaban los vecinos, daban "el albazo y asalto" perpetrando muchas matanzas. ${ }^{24}$

En 1724 y en relación al trato a los indios, el virrey ordenaría a Arriaga y en general a los gobernadores y capitanes de todos los presidios y fronteras novohipanos, que no se hiciera guerra ofensiva contra los indios gentiles, sino defensiva y que se les atrajera sin violencia al gremio de la fé católica. J uzgaba, que sólo sería tolerable ejecutar algunas muertes en caso de defensa propia, pero que si se hiciera sin esta moderación sería reprensible, como también lo era el que los oficiales y soldados indisciplinados salieran, con la excusa de hacer expediciones, a cazar indios como si fueran alimañas. $^{25}$

Arriaga insistiría en que la guerra que se hizo a los indios fue justa y defensiva con lo cual no sólo instauró la paz en esa provincia, sino en Mazapil correspondiente al distrito de la Audiencia de Guadalajara, en Parras (Nueva Vizcaya) y en Coahuila, ya que los indios en sus incursiones se adentraban en tierras limítrofes a Nuevo León. Y que su objetivo al hacer las campañas no era el de matar a los indios, sino "el de sose-

AGI, Audiencia de Guadalajara, leg. 173. Carta de fray Miguel Pacheco a fray Sebastián de Torres, Cerralvo, 5 de septiembre de 1723, ibid. Certificación de J osé Antonio Fernández Vallejo, Santiago de las Sabinas, 14 de noviembre de 1724, ibid.

24 Carta de Villalobos al Rey, México, 4 de octubre de 1726, AGI, Audiencia de Guadalajara, leg. 173. Acerca de las alianzas específicas que para la guerra hacían los indios con otras tribus en las juntas o tlatoles, (SHERIDAN PRIETO, 2002, p. 22-23). Información sobre el protector Villalobos y las circunstancia de su cese, (BAEZA MARTIN, 2010, p. 209-237).

${ }^{25}$ Carta de Casafuerte al gobernador de Nuevo León, México, 22 de abril de 1724, AGI, Audiencia de 
garlos y refrenarlos" para que no quitaran la vida a los moradores y llevaran la justa pena de los que ellos habían exterminado, y eso, no excedía en manera alguna de los precisos límites de guerra justa y defensiva. En cuanto a los indios pequeños que se cogían, se llevaban a familias cristianas y de buenas costumbres para que lo educaran, pues si se metían en los pueblos podrían huir y volver a su "barbaridad, fiereza, indevoción y apostasía”. ${ }^{26}$

\section{¿Una Sentencia J usta?}

En el transcurso del litigio, antes de que se fallara la sentencia, estando Arriaga suspendido del ejercicio de su ministerio y teniendo que ir a Mexico a hacer los descargos, el virrey designó como gobernador interino a Pedro de Sarabia Cortés. El nuevo gobernador estuvo ejerciendo el cargo desde el 12 de diciembre de 1724 hasta el 13 de enero de 1727 cobrando sólo la mitad del sueldo asignado a los propietarios. A partir de esa fecha, sin estar finalizada la causa, pero constando por ella el mal proceder de García de Pruneda, la máxima autoridad virreinal lo mandó arrestar como ya hemos expuesto, resolviendo que Arriaga le presentara tres candidatos para teniente de gobernador y sirviera la plaza de su cuenta. El interesado puso en primer lugar al sargento mayor Pedro de Elizondo que fue el que eligió el virrey. ${ }^{27}$

No obstante, estando este pleito aún sin determinar y discurriendo Arriaga que había justificado suficientemente los capítulos puestos por García de Pruneda, pediría al monarca que se le reintegrara en el uso y ejercicio de su empleo durante el período que le restaba para completar los cinco años por el que se le concedió. Y es que le había llegado la noticia a través de su hermano Francisco de Arriaga, cura de la parroquia de la Santa Veracruz de México, y de un ejemplar de la Gaceta de Madrid de 6 de agosto de 1726, que el rey había provisto dicho gobierno. ${ }^{28}$

Las pretensiones de Arriaga se malograron, a pesar de que el visitador de los presidios internos, el brigadier Pedro de Rivera, había avisado al virrey de la necesidad de su restitución para el reparo de las hostilidades que los indios seguían haciendo en Nuevo León. Sin haber tenido en cuenta el estado de dicho pleito, esa plaza estaba ya asignada por la Corona desde febrero de 1726 al capitán Miguel de Irigoyen y Echeni-

Guadalajara, leg. 173.

26 Testimonio del escrito de Arriaga, AGI, Escribanía de Cámara, leg. 204A.

27 Memorial de Arriaga al Virrey (s/f), AGI, Escribanía de Cámara, 204A. Certificación de los Oficiales Reales de México, México, 15 de febrero de 1730, AGI, Audiencia de Guadalajara, leg. 173. Parece que también estuvieron un tiempo como tenientes del gobernador Arriaga, Pedro de la Barreda y Francisco J avier de Escamilla, a lo que se opuso García de Pruneda.

28 Petición deJ uan de Meñaca en nombre de J uan J osé de Arriaga al Rey (s/f) y Certificación de Luis 
que por estimarse que quedaba poco tiempo para cumplirse dicho quinquenio. Irigoyen, en la creencia de que una vez que presentara en México los títulos se le daría posesión, había dejado ya su puesto en el Regimiento de Caballería de Borbón, contraído deudas para el viaje y gestionado la licencia de embarque en la flota de los azogues próxima a salir. Al conocer las intenciones de aquel y el perjuicio que podría ocasionársele con su vuelta, pediría al rey hacia 1728 que se le recibiera en dicho puesto y a Arriaga se le diera otro, o bien se le confiriese a él la alcaldía mayor de Xicayan próxima a vacar. ${ }^{29}$

Una vez examinados los expedientes del proceso, el virrey el 20 de diciembre de 1729 con el parecer del Auditor José Gutiérrez de la Peña y la asistencia del oidor J osé Fernández Veitia Linaje pronunciaría la sentencia. Declaró que Luis García de Pruneda "había probado bien y cumplidamente" lo que le convino justificar, en cambio Arriaga no lo hizo de las excepciones que opuso. El fallo fue el siguiente:

1) Por las injurias a Luis García de Pruneda: privación perpetua del oficio de gobernador y de cualquier otro relacionado con la adminisrtración de justicia. Destierro perpetuo del Nuevo Reino de León y su jurisdicción. Multa de 2.000 maravedíes aplicados, según las Leyes, la mitad para la Cámara de S.M y la otra mitad para el querellante. Pago a éste de todos los daños, pérdidas y atrasos derivados de dichas injurias y en las costas procesales y personales conforme a arancel, así como de 2.600 pesos de un vale que Arriaga le otorgó a su favor más un $10 \%$ de interés.

2) Por contravenir las Leyes que prohibían el trato y comercio: privación de dicho oficio. Pérdida de todo lo que trató, contrató y las granjerías que tuvo en dicha jurisdicción, más 1.000 ducados de plata aplicados por tercias partes conforme a la Ley, es decir, 2/ 3 para la Cámara y 1/3 para García de Pruneda que lo denunció.

3) Por dar su consentimiento para las muertes y ventas de indios sin haber hecho causa contra el capitán García de Quintanilla ni otros que las cometieron: multa de 2.000 pesos para la Cámara y 1.000 por permitir que se vendieran los indios por piezas.

Casafuerte, para evitar que los indios fueran vendidos y repartidos en perpetua servidumbre, mandó expedir despacho a los alcaldes ordinarios de Monterrey para que hicieran comparecer ante su presencia a todos los que se hallaran entregados en dicha forma. Por medio de un intérprete tendrían que hacerles saber que no eran esclavos y 
que podían vivir cristianamente en las poblaciones como hombres libres "en cuanto no sea volver al error de los bárbaros enemigos porque, en tal caso, se les castigará conforme a las leyes, procediendo contra ellos como rebeldes apóstatas".

De la misma forma, mandaba que a los curas, misioneros o ministros de doctrinas se les encargara que explicasen a los indios la distinción entre el vasallaje y la esclavitud. De cómo el rey no quería que fueran esclavos, sino tenerlos bajo su protección como a hijos y buenos vasallos, "cuidando de su salud espiritual y corporal y que no vagueen en las asperezas de los yermos, viviendo como fieras y brutos sin ley ni conocimiento de Dios". ${ }^{30}$

En contraste y, a pesar, como hemos visto, de todas las expresiones en contra de muchas de los actos en el ejercicio de sus cargos en esa región del general Luis García de Pruneda - - que así se le calificaba por haber sido gobernador y capitán general- , en su memoria de servicios certificada por escribanos de México y por Francisco de Mier y Noriega a quién, como ya mencionamos, le costeó la plaza, se recoge que había demostrado con sus operaciones en ese territorio lo siguiente:

Ser el único que había hecho prevalecer la justicia y la razón del pobre desvalido, al que debe la ciudad de Monterrey el lustre que tiene y el consuelo en que todos vivían, sujetando muchos intentos dañosos que hubieran ejecutado los jueces si el dicho Don Luis no hubiera sacado la cara en su justa defensa, por lo cual los gobernadores y sus parciales le tenían ojeriza y procuraban desabrimientos dirigidos a que se ausentase para no ser estorbo a sus intentos, que a ser dable, quedaban desconsolados y en peligro de perderse así los pueblos reducidos como los naturales, que le buscaban para su asilo y recurso todos como padre $[\ldots]^{31}$

El que fuera protector de indios, Villalobos, logró finalmente que se le concediera un cargo: la alcaldía de Huamanga en Perú (BAEZA MARTÍN, 2010, p. 234).

Arriaga manifestaría que había justificado suficientemente que las imputaciones de García de Pruneda hacia su persona eran falsas y habían sido hechas con testigos que eran "sus muleros, chivateros, arrieros, correos, todos sus criados y hombres indignos". Además, constaba por los autos que había comprado a algunos testigos para que declararan en contra suya, suministrándole a uno 23 pesos, a otro un vale de 50 eincluso a un clérigo 200 ó 300 pesos, dándose el caso de que uno de los que quiso sobornar, Alejandro Urón, se negó a la proposición de aquel.

30 Sentencia de Arriaga, México, 20 de diciembre de 1729, AGI, Escribanía de Cámara, leg. $204 \mathrm{~A}$.

31 Relación de los méritos de D. Luis García de Pruneda, Madrid, 15 de marzo de 173, AGI, Indiferente General, 148, N. 23. 
También era palpable que muchos de los deponentes estaban emparentados o tenían intereses comunes con García de Pruneda. Por poner unos ejemplos, diremos que Francisco y Cristóbal Cantú eran primos hermanos de su mujer; J uan González de Ochoa estaba casado con Andrea de León, prima hermana igualmente de su esposa; Juan García de Zaldívar era primo de J osé García Guerra, yerno de D. Luis; Ignacio García Guerra, hermano del anterior; Nicolás Flores, era sirviente del susodicho y uno de los grandes enemigos de Arriaga. ${ }^{32}$

Por su parte García de Pruneda aseguraba con testigos que el hermano cura del gobernador estaba haciendo mucho por él. Que el marques de Villapuente, junto con los ganaderos y otros, así como los jesuítas, el visitador de los presidios internos Pedro de Rivera e incluso el virrey y su secretario Francisco Fernandez Molinillo, estaban a favor de Arriaga. 33

El afán de venganza de algunos testigos sería otra de las características de este pleito. Gregorio Treviño, alcalde mayor del Valle del Huajuco en Monterrey, afirmaba que era público y notorio que uno de los interrogados, J osé Félix de Almandos, capitán del presidio de San Gregorio de Cerralvo, le había hecho varias instancias a Arriaga para que intercediese a su favor ante el virrey a fin de que éste le confirmara el cargo. El gobernador no estimó oportuno hacerlo y desde entonces se mostró Almandos como su "más cruel enemigo". Algo semejante ocurría con Ignacio Guerra, hermano del yerno de García de Pruneda, quien le mostraba "una pasión y odio mortal” desde que le borró la plaza de alférez justificadamente, por sus grandes desafueros. ${ }^{34}$

Arriaga recurriría la sentencia ante el Consejo de Indias. Consiguió que, previa fianza, se le levantara la carcelería en Madrid donde se había refugiado sin haber abonado a su contrincante las multas que se le impuso en la sentencia. Del mismo modo, logró que se le diera licencia para ir a México a por los autos originales del litigio otorgándosele para este efecto un plazo de ocho meses y con la condición de que no fuera al Nuevo Reino de León, como había solicitado su rival. Sin embargo, ninguno de los numerosos documentos consultados nos ha dado indicios que permitan suponer que pudiera haber sido indultado parcial o totalmente por el Consejo, ni que se le hubiera concedido otro empleo.

32 Certificación de Juan Álvarez de la Plata, México, 26 de junio de 1725, AGI, Audiencia de Guadalajara, leg. 118. Certificación de Gregorio Treviño, Valle del Huajuco, 10 de mayo de 1727, AGI, Escribanía de Cámara, 204A.

${ }^{33}$ Certificación de Juan Álvarez de la Plata. México, 26 de junio de 1725 y Petición de J osé de Liticia en nombre de Luis García de Pruneda a S.M.(s/f), AGI, Audiencia de Guadalajara, 118.

${ }^{34}$ Certificación de Gregorio Treviño, Valle del Guajuco, 10 de mayo de 1727. AGI, Escribanía de Cámara, 204 A. 
El 9 de junio de 1729, unos siete meses antes de conocerse esta sentencia, el monarca le asignó el gobierno de Nuevo León a Bernardino de Meneses Monroy y Mendoza, conde de Peñalva y caballero de la Orden de Santiago, por suponer que estaba próximo a extinguirse el plazo por el que fue designado Arriaga. En esta ocasión el oficio parece que no se benefició, sino que fue una merced en atención a llevar 30 años sirviéndo a la Corona en Nueva España con diferentes empleos políticos y militares, después de que en España había sido regidor perpetuo de la Villa de Madrid y gentil hombre de Cámara del rey. Al igual que denunció Arriaga cuando tomó posesión, el conde de Peñalva informaría a la Corona que desde que entró en el gobierno en junio de 1730 halló "muy fatigados a los vecinos y reducidos a suma pobreza por las continuas hostilidades de los indios bárbaros, que le obligan a no arrimar las armas”. Asentaba que pondría las más eficaces medidas para refrenarlos y lograr su reducción "por los medios más suaves". ${ }^{35}$

\section{Breve Conclusión}

El suceso que hemos analizado refleja las vigorosas redes de dominio, las intrigas, corrupción, violencias e intereses de algunas de las familias asentadas desde tiempo remotos en esas fronteras, lo cual se tradujo en un despotismo que sufrieron los vecinos y todos aquellos que no se doblegaron a sus voluntades. Poder favorecido, entre otras cosas, por los servicios de algunos de sus miembros a la Corona y que serían luego remunerados con importantes cargos políticos, judiciales o administrativos que desempeñaron, en muchos casos, de forma abusiva Y, en especial, por la acumulación de empleos en un mismo individuo, conseguidos mediante una determinada cantidad de dinero, lo que evidenciaba un descontrol por parte del gobierno de Madrid en la concesión de oficios y la necesidad de la Real Hacienda de recaudar fondos. A todo esto se sumaba la despreocupación de las autoridades, la lejanía con los poderes centrales de México y la lentitud burocrática que impedía que se pudieran vigilar más de cerca y poner pronto remedio a estas irregularidades.

El poder local, representado en el tiempo en que se basa este estudio, fundamentalmente, por los García de Pruneda, superó al que tenía Arriaga como gobernador, quien, además, se vió envuelto en una encerrona de difícil escapatoria. La presión ejercida por aquel en su contra ante el máximo gobernante del virreinato, sus cartas a la metrópoli queriendo demostrar que no se le estaba haciendo justicia en México y su

35 Real Título de gobernador y capitán general del Nuevo Reino de León al conde de Peñalva, El Puerto de Santa María, 9 de junio de 1729, AGI, Contratación, 5477, N.185. Carta del conde de Peñalva al Rey y a J osé Patiño, Monterrey, 24 de julio de 1730, AGI, Audiencia de Guadalajara, leg. 300 . 
interesada unión a la causa del protector general de indios de Nuevo León, amen del apoyo que le proporcionaron parientes, amigos y otras gentes de esa provincia y de México, de forma no siempre legal, coadyuvaron a que el resultado del pleito tuviese ese malogrado desenlace para Arriaga.

La paz con los indios en aquellos límites era precisa por varios motivos: para continuar con el avance colonizador, evitar la irrupción de los enemigos de la Corona en esas tierras y extender la evangelización; para la seguridad y sosiego de sus moradores; el resguardo de sus cosechas, ganados y pertenecias y, evidentemente, para la obtencion de mano de obra que con su trabajo propulsara el desarrollo y la actividad agrícola, ganadera y minera de la región y, con ello, el flujo comercial con la capital y otras regiones novohispanas, en lo cual había mucha gente interesada de dentro y fuera de esa región. Sin embargo, este equilibrio entre las relaciones colonos-indios era complicada debido al propio sistema colonial.

Las reformas que se implantaron por mandato de la Corona y el gobierno virreinal mediante la comisión que se dio al alcalde del Crimen de la Audiencia de México Francisco Barbadillo Vitoria no gustaron a algunos vecinos. Se sentían defraudados por haber tenido que desprenderse de tierras para la formación de los pueblos de indios y de no tener a éstos a su servicio, gratuitamente o a cambio del mínimo sustento, en las congregas, como se hacía antes de los cambios.

El rigor de algunos gobernadores o de sus capitanes dirigidos a sujetar las hostilidades de los indios, así como el ejercicio de la venta de éstos, era práctica habitual en aquellas fronteras antes de llegar Arriaga, aunque se ejercía con menor intensidad que en tiempos antiguos. El cese de este gobernador no supuso un cambio drástico de ese contexto. El problema de los ataques de los indígenas subsistiría por largos años, ya que el sistema de defensa colonial era insuficiente, la opresión de algunas autoridades y habitantes hacia ellos también y las medidas tomadas tardías y lentas de aplicar. Además, muchos indios se resistieron permanentemente a estar bajo el dominio de los españoles y algunos de los ya adoctrinados huían de los pueblos para confederarse con los otros y cometer sus desmanes, aunque luego ofrecieran la paz, a menudo ficticia.

\section{Referencia}

BAEZA MARTÍN, Ascensión. Gobierno, colonos e indios en el Municipio de Nuestra Señora de Monterrey (Nuevo Reino de León, 1716-1740). In: GARCÍA BERNAL, Manuela Cristina; OLIVERO GUIDOBONO, Sandra (Coord.). El Municipio Indiano: relaciones interétnicas, económicas y sociales. Sevilla: Publicaciones de la Universidad de Sevilla, 2009. p. 151- 165. 
BAEZA MARTÍN, Ascensión. Presión e intereses en torno al cargo de protector general de indios del Nuevo Reino de León: el caso de Nicolás de Villalobos, 1714-1734. Anuario de Estudios Americanos, Sevilla, v. 67, n. 1, p. 209-237, 2010.

BURKHOLDER, Mark A.; CHANDLER, D.S. De la impotencia a la autoridad: la Corona española y las audiencias en América 1687-1808. México: Fondo de Cultura Económica, 1984.

CAVAZOS GARZA, Israel. Catálogo y sintesis de los protocolos del archivo municipal de Monterrey 1700-1725. Monterrey: Centro de Estudios Humanísticos, 1973.

CAVAZOS GARZA, Israel. Catálogo y síntesis de los protocolos del archivo municipal de Monterrey, 1726-1756. Monterrey: Instituto Tecnológico y de Estudios Superiores, 1986.

COVARRUBIAS, Ricardo (Comp.). Gobernantes de Nuevo León, 1582-1961. Monterrey, 1961.

GERHARD, Peter. La frontera norte de la Nueva España. México: UNAM, 1996.

HOYO, Eugenio del. Historia del Nuevo Reino de León (1577-1723). Monterrey:

Publicaciones del Instituto Tecnológico y de Estudios Superiores de Monterrey, 1972. 2. v.

J IMÉNEZ NÚÑEZ, Alfredo. El gran norte de México: una frontera imperial en la Nueva España (1540-1820). Madrid: Tebar, 2006.

MONTEMAYOR HERNÁNDEZ, Andrés. La congrega o encomienda en el Nuevo Reino de León. Humanitas, Nuevo León, n. 11, p. 539-575, 1970.

NAVARRO GARCÍA, Luis. Don J osé de Gálvez y la comandancia general de las provincias internas del norte de Nueva España. Sevilla: Publicaciones de la Escuela de Estudios Hispano-Americanos, 1964.

PEÑA GUAJ ARDO, Antonio. La economía novohispana y la élite local del Nuevo Reino de León en la primera mitad del siglo XVIII. México: Consejo para la Cultura y las Artes de Nuevo León, 2005.

SHERIDAN PRIETO, Cecilia. Reflexiones en torno a las identidades nativas en el noreste colonial. Relaciones, v. 23, n. 92, México, p. 75-106, 2002. Disponible en: <http:/ / redalyc.uaemex.mx/ redalyc/ pdf/ 137/ 13709205.pdf>. Acceso en: 12 set. 2010.

VALDÉS, Carlos Manuel. La gente del Mezquite: los nómadas del noreste en la colonia. México: Centro de Investigaciones y Estudios Superiores en Antropología Social, 1995.

ZAVALA, Silvio. Entradas, congregas y encomiendas de indios en el Nuevo Reino de León. Sevilla: Secretariado de Publicaciones de la Universidad de Sevilla, 1992.

Colaboración recibida en 04/ 03/2011 y aprobada en 18/ 10/ 2011. 